\title{
Attitude similarity and evaluation of an athletic team
}

\author{
K. ELAINE ROYAL, GINA C. LOMBARDI, and HAROLD D. WHITESIDE \\ Middle Tennessee State University, Murfreesboro, Tennessee
}

\begin{abstract}
This study extends the effect of attitude similarity or dissimilarity upon the evaluation of others to the athletic arena. Thirty-eight male high school varsity basketball athletes rated a hypothetical attitudinally similar college team more positively than an attitudinally dissimilar hypothetical college team on five of nine dependent measures. Implications arise concerning the recruiting and counseling of athletes with respect to the maintenance of team cooperation and morale.
\end{abstract}

For many years, much social psychological research concerned with the determinants of interpersonal attraction has focused on the extent to which a person holds attitudes and opinions similar to one's own (Bryne, 1961, 1971). In addition to influencing attraction responses, similarity of attitudes has been shown to affect other aspects of interpersonal evaluative behavior. For example, one is more likely to evaluate an attitudinally similar stranger as being more intelligent, better adjusted, and more moral than an attitudinally dissimilar stranger (Bryne, 1961). In addition, other research projects have shown that an outsider's attraction to a group can be influenced by the degree to which the members of the group express attitudes and opinions agreeing with the outsider's own views (Good \& Nelson, 1973). For instance, Royal and Golden (1981) found that subjects rated a hypothetical attitudinally similar work group more positively than an attitudinally dissimilar work group.

We were interested in examining the influence of attitude similarity on attraction and evaluations in the athletic arena. It was hypothesized that attitude similarity would influence high school athletes' liking for or attraction to a hypothetical college team and their desire to become a member of that hypothetical college team. It was further hypothesized that high school athletes would evaluate an attitudinally similar college team as being more intelligent, better adjusted, more cooperative, harder working, more enthusiastic, feeling more at ease, and having higher quality players than an attitudinally dissimilar team.

\section{METHOD}

The subjects were 38 male high school athletes who were members of varsity basketball teams at two public high schools in the middle Tennessee area. The subjects completed a 16-item survey of attitudes dealing with topics such as mainstreaming children in public schools, prayer in public schools, strict discipline of children, and social topics of col-

Correspondence may be addressed to Harold D. Whiteside, Psychology Department, P.O. Box 87, Middle Tennessee State University, Murfreesboro, TN 37132. lege life. Approximately 3 weeks later, each subject received a packet containing an instruction sheet, a survey of team attitudes, and a team evaluation scale. The following instructions were given to the subjects:

A number of previous studies have shown that individuals can make accurate judgments about others on the basis of knowing some of their attitudes. Our present concern is determining whether or not impressions can be formed about an athletic team on the basis of knowing some of the attitudes held by most of the players on the team. Each of you has received an attitude survey which has been marked to show the opinions held by most of the players on a particular college team. All of these individuals are strangers to you. Please study these attitudes carefully and then fill out the Team Evaluation Scale.

The survey of team attitudes included the same 16 items comprising the survey of attitudes previously completed by the subjects. The survey of team attitudes each subject received had been randomly filled out by the experimenter so that team attitudes were either $25 \%$ (4 out of 16 items) or $75 \%$ (12 out of 16 items) similar to each subject's own attitudes.

The team evaluation scale was modeled after the Interpersonal Judgment Scale (Bryne, 1971) used extensively in research on attraction to a similar stranger. On nine 7-point items, the subjects were asked to make judgments on the following topics (the dependent variables): intelligence, adjustment, personal feelings (liking), desire to join the team, quality of players, team cooperation, team enthusiasm, feeling relaxed with the team, and desire to work hard.

\section{RESULTS}

Table 1 shows the comparison of the subjects' evaluations of attitudinally similar and dissimilar teams on each of the dependent variables. The influence of attitude similarity was confirmed for the following variables: intelligence, adjustment, desire to join the team, team cooperation, and feeling relaxed with team.

\section{DISCUSSION}

Since this study revealed that only five variables out of nine were significantly influenced by attitude similarity, it did not reveal as powerful or as widespread an influence as was shown in previous studies. There may be several reasons for this disparity. For instance, the subjects in the present study were informed that they did not know the team they were evaluating; however, since the experimenter was a student from the local university, it is possible that subjects believed that they were rating basketball players from that team. Another possible factor might have been that in the typical similarity-attraction studies there is only 
Table 1

Evaluation Responses as a Function of Attitudinal Similarity

\begin{tabular}{lcccccc}
\hline & \multicolumn{2}{c}{ Similar $(n=20)$} & & \multicolumn{3}{c}{ Dissimilar $(n=18)$} \\
\cline { 2 - 3 } Evaluation Response & $M$ & $S D$ & & $S D$ & $F(1,36)$ \\
\hline Intelligence & 5.20 & 1.15 & & 4.28 & 1.28 & $5.49^{*}$ \\
Adjustment & 5.30 & 1.45 & & 3.72 & 1.56 & $10.38^{*}$ \\
Personal feelings & 6.15 & 0.99 & & 5.44 & 1.46 & 3.09 \\
Desire to join team & 6.20 & 1.36 & & 4.33 & 2.30 & $9.49^{*}$ \\
Qaulity of players & 5.60 & 1.43 & & 5.17 & 1.69 & 0.73 \\
Team cooperation & 5.50 & 0.95 & & 3.50 & 1.76 & $19.63^{*}$ \\
Enthusiasm & 5.85 & 1.35 & 5.00 & 1.41 & 3.59 \\
Feeling relaxed & 5.70 & 1.34 & 4.39 & 1.94 & $5.95^{*}$ \\
Working hard & 5.50 & 1.50 & 4.44 & 1.89 & 3.67 \\
\hline
\end{tabular}

${ }^{*} p<.05$.

a 1-week lapse between testing sessions, but in the current study there was a 3-week lapse.

The present study indicates that perceived attitude similarity can influence the high school athlete's impression of a college team. With the recent emphasis on the need for sports psychologists in the area of counseling athletes (Schell, Hunt, \& Lloyd, 1984), it may be of importance to sports psychologists, coaches, and athletes and their families to consider placing athletes with teams that have attitudes similar to their own in order to enhance team cooperation, morale, and personal life satisfaction.

\section{REFERENCES}

BRYNE, D. (1961). Interpersonal attraction and attitude similarity. Journal of Abnormal \& Social Psychology, 62, 713-715.

Bryne, D. (1971). The attraction paradigm. New York: Academic Press.

Good, L. R., \& Nelson, D. A. (1973). Effects of person-group and intra-group attitude similarity on perceived group attractiveness and cohesiveness. Psychological Reports, 33, 551-560.

RoYAl, K. E., \&olden, S. B. (1981). Attitude similarity and attraction to an employee group. Psychological Reports, 48, 251-254.

SChell, B., HUNT, J., \& LLYY, C. (1984). An investigation of the future market opportunities for sport psychologists. Journal of Sport Psychology, 6, 335-350.

(Manuscript received February 12, 1990.) 